\title{
Priming of circulating human eosinophils following late response to allergen challenge
}

\section{To the Editor:}

I read, with interest, the article entitled: "Priming of circulating human eosinophils following late response to allergen challenge", by EvANs et al. [1]. I fully agree with the conclusion of the authors that eosinophils are primed in the peripheral blood of allergic asthmatic patients after allergen challenge. However, I have a few points I would like to raise.

The authors suggest that allergen challenge is required for the identification of primed eosinophils in the circulation. However, several studies from other laboratories have shown that eosinophils in the peripheral blood of allergic asthmatics exhibit a primed phenotype in the context of cell migration and transendothelial migration [2-5]. The chronic allergic inflammatory response in the airways (chronic exposure to allergens in normal daily life?) probably induces a partial primed phenotype of the peripheral blood eosinophils. This in vivo primed phenotype is induced in eosinophils from normal donors by $\mathrm{T}$-cell/mast cell derived cytokines, such as interleukin-5 (IL-5) and granulocyte/macrophage colony-stimulating factor (GM-CSF) [6, 7]. The finding that eosinophils from allergic asthmatics exhibit increased response towards platelet activating factor (PAF) in the context of the nicotinamide adenine dinucleotide phosphate (reduced) (NADPH)-oxidase is in agreement with an earlier study [8] describing enhanced PAF-induced chemiluminescence responses in eosinophils from allergic asthmatics compared to normal control cells. These studies are relevant and are not discussed in the article.

In the article, it is stated that this is the first publication to describe an enhanced priming of eosinophils after allergen challenge. However, we have published a study [9] describing the effects of allergen challenge on the priming of eosinophils isolated from the blood of allergic asthmatics. Indeed, the priming of the eosinophils appeared to be more pronounced after allergen challenge. Moreover, the elegant work of CARLSON et al. [10] described in vivo priming of peripheral blood eosinophils of pollen allergic patients during the pollen season. This is a very good model for the effect of allergen challenge on the priming status of eosinophils in vivo.

The presence of eosinophil-priming cytokines in the peripheral blood of patients with allergic asthma has been adequately described $[11,12]$. These studies have shown that the serum of these patients can induce enhanced survival and functionality of eosinophils. This might be involved in the enhanced survival seen by the authors in their article. These articles are not referenced.

In conclusion, the article would have been more balanced if the aforementioned studies had been discussed in the context of the findings described. For clarity, I have referenced several studies as illustration but I did not intend to review all the relevant literature.

\section{References}

1. Evans DJ, Lindsay MA, O'Connor, Barnes BJ. Priming of circulating human eosinophils following late response to allergen challenge. Eur Respir J 1996; 9: 703-708.

2. Sehmi R, Cromwell O, Wardlaw AJ, Moqbel R, Kay AB. Interleukin-8 is a chemoattractant for eosinophils purified from subjects with a blood eosinophilia but not from normal healthy subjects. Clin Exp Allergy 1993; 23: 1027-1036.

3. Sehmi R, Wardlaw AJ, Cromwell O, Kurihara K, Waltmann $\mathrm{P}, \mathrm{Kay} \mathrm{AB}$. Interleukin-5 selectively enhances the chemotactic response of eosinophils obtained from normal but not eosinophilic subjects. Blood 1992; 79: 2952-2959.

4. Warringa RAJ, Mengelers HJJ, Kuijper PHM, Raaijmakers JAM, Bruijnzeel PLB, Koenderman L. In vivo priming of platelet-activating factor-induced eosinophil chemotaxis in allergic asthmatic individuals. Blood 1992; 79: 1836-1841.

5. Moser R, Fehr J, Bruijnzeel PLB. IL-4 controls the selective endothelium-driven transmigration of eosinophils from allergic individuals. J Immunol 1992; 149: 1432-1438.

6. Ebisawa M, Liu MC, Yamada T, et al. Eosinophil transendothelial migration induced by cytokines. II. Potentiation of eosinophil transendothelial migration by eosinophil-active cytokines. J Immunol 1994; 152: 45904596.

7. Warringa RAJ, Koenderman L, Kok PTM, Kreukniet J, Bruijnzeel PLB. Modulation and induction of eosinophil chemotaxis by granulocyte-macrophage colony-stimulating factor and interleukin-3. Blood 1991; 77: 2694-2700.

8. Koenderman L, Bruijnzeel PLB. Increased sensitivity of the chemoattractant-induced chemiluminescence in eosinophils isolated from atopic individuals. Immunology 1989; 67: 534-536.

9. Warringa RAJ, Mengelers HJJ, Raaijmakers JAM, Bruijnzeel PLB, Koenderman L. Upregulation of formylpeptide and interleukin- 8 induced eosinophil chemotaxis in allergic asthmatic individuals. J Allergy Clin Immunol 1993; 91: 1198-1205.

10. Carlson M, Hakansson L, Kampe M, Stalenheim G, Peterson C, Venge P. Degranulation of eosinophils from pollen-atopic patients with asthma is increased during pollen season. J Allergy Clin Immunol 1992; 89: 131-139.

11. Walker C, Virchow JCJ, Bruijnzeel PLB, Blaser K. Tcell subsets and their soluble products regulate eosinophilia in allergic and nonallergic asthma. J Immunol 1991; 146: $1829-1835$.

12. Hakansson L, Rak S, Dahl R, Venge P. The formation of eosinophil and neutrophil chemotactic activity during a pollen season and after allergen challenge. J Allergy Clin Immunol 1989; 83: 933-939.

\section{Koenderman}

Dept Pulmonary Diseases, University Hospital Utrecht, Heidelberglaan 100, NL-3584 CX Utrecht, The Netherlands. 


\section{REPLY}

\section{From the authors:}

We agree with Koenderman that eosinophils from asthmatic individuals demonstrate evidence of in vivo priming, although we do not suggest that laboratory allergen challenge is unique in producing this state. Our work has simply shown that eosinophils from asthmatic patients have increased functional activity and survival following allergen challenge, and that this is in keeping with a priming response.

The studies cited in his correspondence clearly show the specific effects of a number of relevant cytokines upon individual eosinophil functions, such as chemotaxis. These studies demonstrate the complexity of the issue of priming, and collectively these data point to a primed phenotype of eosinophil in this group of patients. However, the combined consequence of all these effects in the in vivo situation needs to be defined. In our study, we looked at the consequence of allergen challenge in patients and assessed changes in eosinophil function. This ex-vivo experiment demonstrated a clinically important result, namely increases in eosinophil function/ survival associated with late asthmatic response (LAR) to allergen. This is especially valuable in clarifying the conflicting evidence from the aforementioned studies, which have shown both up- and downregulation of cell function (for example the various changes in chemotaxis following exposure to platelet-activating factor (PAF), interleukin (IL)-3, IL-4, IL-5, IL-1 $\beta$, IL-8 and granulocyte/macrophage colony-stimulating factor (GM-CSF)).

Our study, in contrast to the work of WARRINGA et al. [1], showed enhanced responses in circulating eosinophils postallergen challenge to PAF and complement factor 5a (C5a) and that this effect was seen at $24 \mathrm{~h}$. Furthermore, this finding was confined to those individuals showing LAR. In the earlier study by WARRINGA et al. [2], if an examination of the cells at $24 \mathrm{~h}$ following an in vivo priming period had been made, the authors may have seen an increased response and, therefore, a progression from their own $3 \mathrm{~h}$ data. In the study by CARLSSON et al. [3] the changes in eosinophil function are clearly shown, although, in contrast to our experiment, not allied to changes in any clinical parameter, such as lung function.

The issue of eosinophil priming cytokines and their effects on survival has been well-documented in vitro, but there are limited data demonstrating the in vivo effects of allergen challenge on survival of circulating eosinophils, especially looking at the relationship of this phenomenon in parallel with clinical responses to whole lung allergen challenge. The data from WALKER et al. [4] links prolonged survival of eosinophils with GMCSF and IL-5 and demonstrates that these factors are released from activated T-cells and are present in the sera of asthmatic patients. Our study has shown prolonged survival of eosinophils following allergen challenge and serves as a good in vivo demonstration for the pre-existing data. We accept that it would have been valuable to have assayed the sera of our patients postallergen for these mediators to confirm this mechanism.

\section{References}

1. Warringa RAJ, Mengelers HJJ, Raaijmakers JAM, Bruijnzeel PLB, Koenderman L. Upregulation of formylpeptide and interleukin-8 induced eosinophil chemotaxis in allergic asthmatic individuals. J Allergy Clin Immunol 1993; 91: 1198-1205.

2. Warringa RAJ, Koenderman L, Kok PTM, Kreukniet J, Bruijnzeel PLB. Modulation and induction of eosinophil chemotaxis by granulocyte/macrophage colonystimulating factor and interleukin-3. Blood 1991; 77: 2694-2700.

3. Carlson M, Hakansson L, Kampe M, Stalenheim G, Peterson C, Venge P. Degranulation of eosinophils from pollen-atopic patients with asthma is increased during pollen season. J Allergy Clin Immunol 1992; 89: 131-139.

4. Walker C, Virchow JCJ, Bruijnzeel PLB, Blaser K. Tcell subsets and their soluble products regulate eosinophilia in allergic and nonallergic asthma. J Immunol 1991; 146: 1829-1855.

D.J. Evans*, M.A. Lindsay**, B.J. O'Connor*, P.J. Barnes**

*Clinical Studies Unit, Royal Brompton Hospital, London, UK. **Dept of Thoracic Medicine, National Heart and Lung Institute, Imperial College of Science, Technology and Medicine, London, UK. 